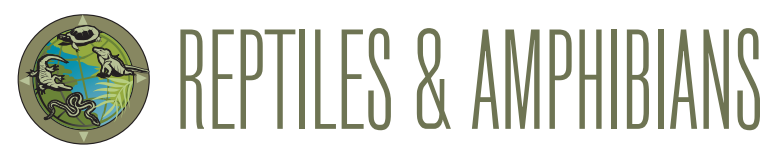

\title{
Record of the Common Leopard Gecko, Eublepharis macularius (Blyth 1854) (Squamata: Eublepharidae), from Kapilvastu District, Nepal
}

\author{
Roshan Panthi ${ }^{1}$, Krishna Ghimire ${ }^{2}$, and Prabhat Kiran Bhattarai ${ }^{3}$ \\ ${ }^{1,3}$ Tribhuvan University, Institute of Forestry, Pokhara Campus, Nepal (panthiroshan0001@gmail.com) \\ ${ }^{2}$ Tri-shakti Community Forest, Kapilvastu District, Nepal
}

$\mathrm{T}_{\mathrm{g}}^{\mathrm{h}}$ he family Eublepharidae (eyelid geckos) comprises six genera and 44 species (Uetz et al. 2020), 11 of which are known to occur in Nepal. This number has recently increased with reports of Common Leopard Geckos (Eublepharis macularius) (Schleich and Kästle 2002; Schleich and Rai 2012; Rawat et al. 2019). These nocturnal geckos are native to Afghanistan, Pakistan, India, Iran, and Nepal (Bonke et al. 2011; Szydłowski et al. 2020). Although largely terrestrial, Common Leopard Geckos will climb trees to take refuge under loose bark but more commonly seek shelter in holes and crevices or under stones and rocks (Khan 2009). Herein we report a new locality record from Kapilvastu District in Nepal.

We encountered a single individual (Fig. 1) at 1428 h on 2 June 2020 on the northern side of the Tri-Shakti Community Forest (93 m asl), Banganga Municipality, Kapilvastu District, Nepal (27²4'57.38"N, 83 8'42.59"E)

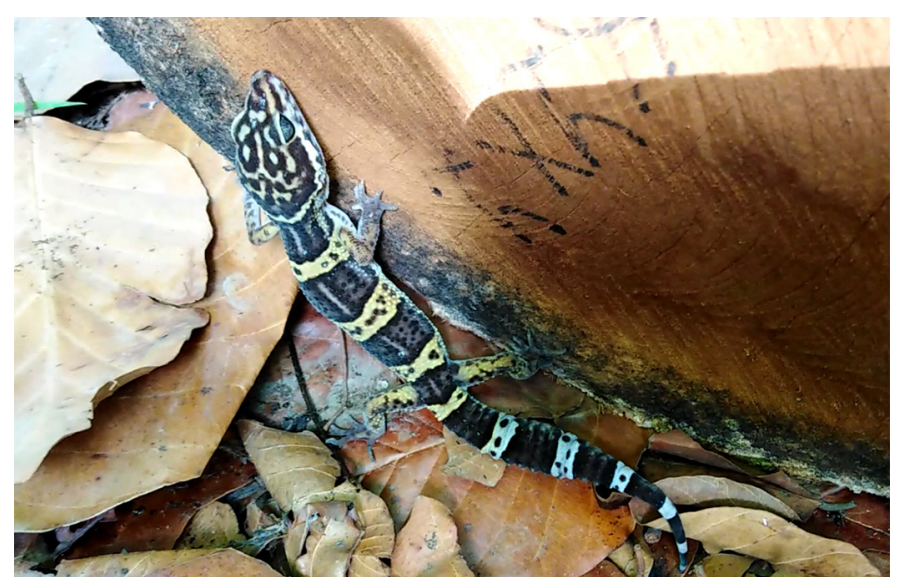

Fig.1. Common Leopard Gecko (Eublepharis macularius) recorded in the Tri-Shakti Community Forest, Banganga Municipality, Kapilvastu District, Nepal. Photograph by Roshan Panthi.

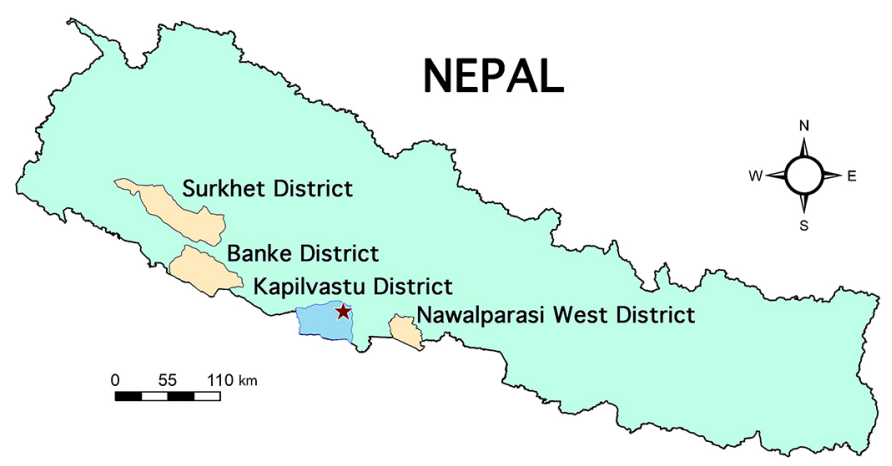

Fig. 2. Map of Nepal showing locality records of the Common Leopard Gecko (Eublepharis macularius). Previous records are from districts indicated by tan color and the new record in Kipilvastu District is marked with a star.

(Fig. 2), during removal of leaf litter for timber extraction. The lizard was resting $1 \mathrm{~m}$ above the ground on a Sal $\log$ in forest dominated by Sal (Shorea robusta), with Saaj (Terminalia elliptica) and Sissau (Dalbergia sissoo) as associated species (Fig. 3). It was photographed, captured, and identified by the presence of tubercles on subdigital lamellae, circular dorsal scales, and the presence of dorsal dark and pale bands with granular spots (Mirza et al. 2014; Rawat et al. 2019). A photographic voucher was deposited in the Zoology and Wildlife Lab, Institute of Forestry, Tribhuvan University, Pokhara, Nepal (017478EM); the identity of the species was confirmed from the photograph by Santosh Bhattarai.

Rawat et al. (2019) had reported the species from Banke, Nawalparasi West, and Surkhet Districts (Fig. 2). All of the records are from Inner Terai Valleys, which comprise the tropical regions of western and midwestern Nepal. The presence of the species in four districts suggests that Common Leopard Geckos are likely to occur in adjoining areas as well. 


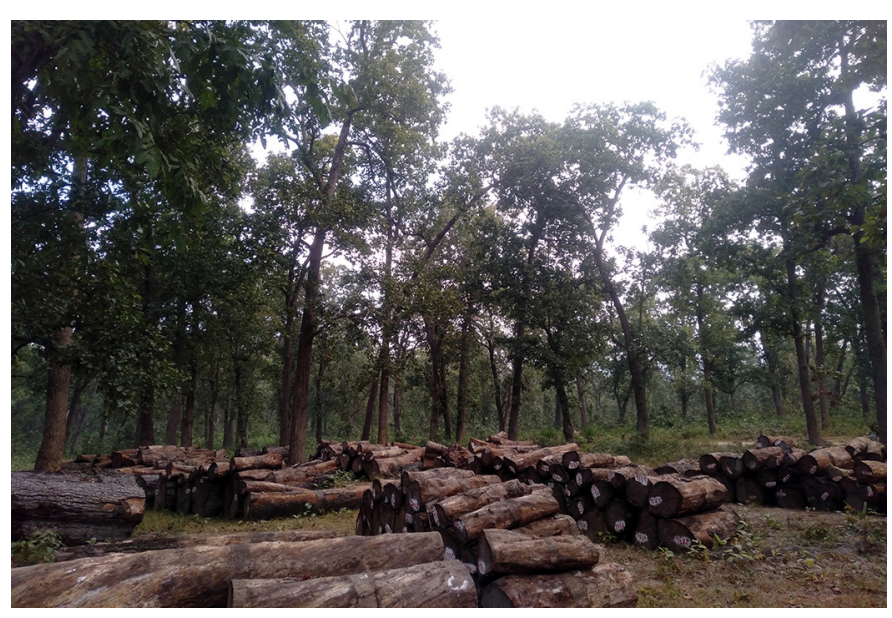

Fig. 3. Habitat where a Common Leopard Gecko (Eublepharis macularius) was recorded in the Tri-Shakti Community Forest, Banganga Municipality, Kapilvastu District, Nepal. Photograph by Roshan Panthi.

However, the apparent rarity of sightings indicates the need for additional herpetofaunal surveys in Nepal. All of these records also are outside protected areas, where logging and excavation are confirmed threats. However, collection for the pet trade is another threat in light of extensive exploitation of populations in neighboring India (Mirza et al. 2014; Rawat et al. 2019).

\section{Acknowledgements}

We thank Santosh Bhattarai for species identification; Chandramani Aryal, Shristee Panthee, Bhuwan Singh Bist, Nabin Pandey, and Nishan KC for helpful suggestions on the manuscript; and the Tri-Shakti Community Forest User Groups for informing us about the species' location.

\section{Literature Cited}

Bonke, R., W. Böhme, K. Opiela, and D. Rödder. 2011. A remarkable case of cannibalism in juvenile Leopard Geckos, Eublepharis macularius (Blyth, 1854) (Squamata: Eublepharidae). Herpetology Notes 4: 211-212.

Khan, M.S. 2009. Natural history and biology of the Leopard Gecko, Eublepharis macularius, in Pakistan. Reptilia 45: 30-35.

Mirza, A.Z., R.V. Sanap, D. Raju, A. Gawai, and P. Ghadekar. 2014. A new species of lizard of the genus Eublepharis (Squamata: Eublepharidae) from India. Phyllomedusa 13: 75-90. doi: https://doi.org/10.11606/issn.2316-9079. v13i2p75-90.

Rawat, Y.B., K.B. Thapa, S. Bhattarai, and K.B. Shah. 2019. First records of the Common Leopard Gecko, Eublepharis macularius (Blyth 1854) (Eublepharidae), in Nepal. Reptiles \& Amphibians 26: 58-61.

Szydłowski, P., J.P. Madej, M. Duda, J.A. Madej, A.S. Kopyłowicz, A.C. Soyta, L. Ilnicka, and P. Duda. 2020. Iridophoroma associated with the lemon frost colour morph of the leopard gecko (Eublepharis macularius). Scientific Reports 10: 5734. doi: 10.1038/41598-020-62828-9.

Uetz, P., P. Freed, and J. Hošek (eds.). 2020. The Reptile Database. <http://www. reptile-database.org/>.

Schleich, H.H. and W. Kästle. 2002. Amphibians and Reptiles of Nepal: Biology, Systematics, Field Guide. A.R.G. Gantner Verlag KG, Ruggell, Lichtenstein.

Schleich, H.H. and K. Rai. 2012. Amphibians and Reptiles of Nepal, Lizards and Crocodiles. A Children's Book. ARCO-Nepal, München, Germany. 